\title{
VARIABILITY OF HUMAN CEREBRAL HEMISPHERES
}

\section{TEMPORAL OPERCULUM}

\author{
Yu.A. Gladilin', O.A. Fomkina' , L.V. Muzurova', \\ E.A. Anisimova', O.Yu. Aleshkina', R.M. Khairullin', \\ O.V. Syrova', V.V. Konnov
}

${ }^{1}$ Human anatomy department, Saratov State Medical University, Ministry of Healthcare of Russian Federation; Russia, 112, Bolshaya Kazachya Street, Saratov, 410012. E-mail: eaan@mail.ru, tel: +79172086603 2 Department of Anatomy, Ulyanovsk State University, Russia, Ulyanovsk, L. Tolstoy Street, 42. E-mail:profkhayrullin@gmail.com, tel: +79176073640

${ }^{3}$ Department of Orthopedic Dentistry; Saratov State Medical University, Ministry of Healthcare of Russian Federation; Russia, 112, Bolshaya Kazachya Street, Saratov, 410012. E-mail: konnovvaleriy@rambler.ru, tel: +79170265176

ABSTRACT - The temporal operculum is a region of the temporal lobe upper surface, which is bounded at the front by transverse temporal gyri, and from behind - by the end of the lateral cerebral sulcus.

AIM OF STUDY: to identify the shape and the dimensional features of the temporal operculum in people aged 1-21. Fixed brain preparations $(n=47)$ were used to measure the depth of the lateral sulcus at the level of the temporal operculum, and the temporal operculum length along its outer edge; the temporal operculum area was calculated as well. The studied material was divided into groups following age periodization: early childhood $(n=8)$; the first period of childhood ( $n=18)$; the second period of childhood ( $n$ $=7)$; adolescence $(n=5)$, youthhood $(n=9)$. The study produced average values for the lateral sulcus depth, the temporal operculum length and area in people aged 1-21. The triangular shape of the temporal operculum has been found to be the most common. The temporal operculum area in early childhood and the first period of childhood, as well as the temporal operculum length in early childhood prevail in the left hemisphere $(p<0.05)$. Viewed from the age aspect, the depth of the lateral sulcus varies less significantly than the length and the area of the temporal operculum. The temporal operculum area correlated more with the operculum length rather than with the depth of the lateral sulcus.

KEYWORDS - temporal operculum, human brain.

\section{INTRODUCTION}

The temporal operculum (operculum temporale) is a region of the temporal lobe upper surface, which is bounded at the front by transverse temporal gyri, and from behind - by the end of the lateral cerebral sulcus (Fig. 1).
Article history:

Received 20 February 2019

Received in revised form 25 March 2019

Accepted 29 March 2019

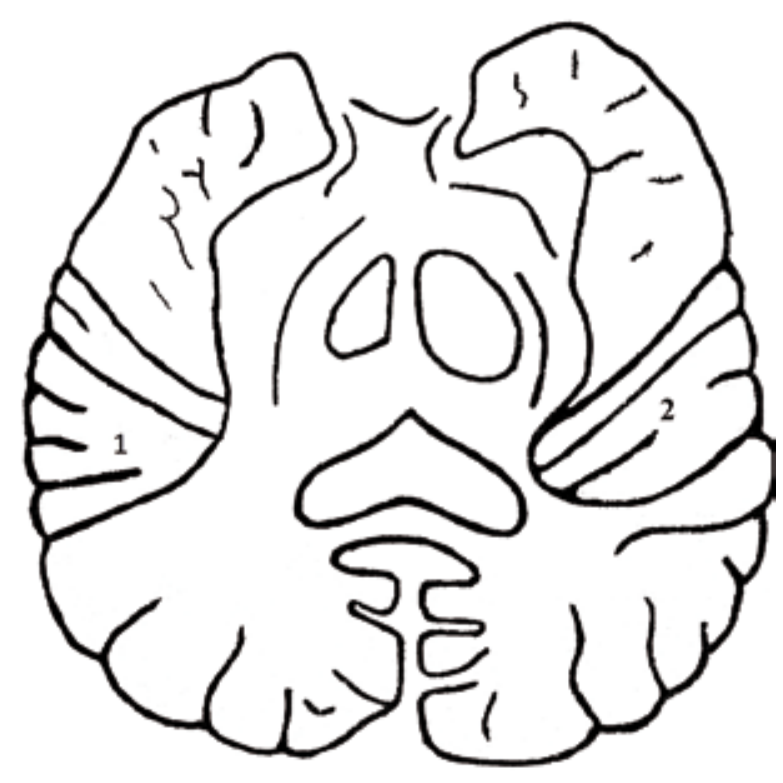

Fig. 1. Temporal operculum layout on the temporal lobe upper surface: 1 - left temporal operculum, 2 - right temporal operculum

Within the temporal operculum, the cortical fields 41 and 42 are localized. These fields, like other fields of the temporal lobe upper surface, are linked to sound perception and are the nuclear zone of the auditory analyzer. Studying these areas of the cortex is an important task within both theoretical and practical sections of medical science, and acts as one of the basic elements for understanding age-related neuromorphology and neurophysiology [1].

Together with the parietal and frontal opercula, the operculum temporale forms the insula operculum, which hides the insular lobe (insula). Recent studies have revealed the importance of the insula in maintaining homeostasis, due to which there is a growth in the interest taken in this area of the cortex [2].

Special literature holds very few works offering a view on the size of temporal operculum. For instance, A.E. Bykanov et al. (2015) in their study provide data on the average thickness of the temporal operculum (distance between the insular posterior point and the lateral surface of the superior temporal gyrus) as equal to $32 \mathrm{~mm}(\min -\max =27-35 \mathrm{~mm})$ [3]. There is data showing the absence of a correlation between 
the size of the temporal operculum and the length of the lateral sulcus and the brain mass [4], as well as the predominance of the temporal operculum area in the left hemisphere of the human brain [5]. The data concerning the length of the temporal operculum and the depth of the lateral sulcus, giving an idea of the longitudinal and transverse dimensions of this cortex area, is rare [4].

To identify the shape and reveal the specific dimensional features of the temporal operculum in people within the age range of $1-21$.

\section{Materials and methods}

Brain preparations with no visible pathological changes were studied, which were obtained through autopsy of 47 corpses from people aged 1-21 years. The brain preparations fixed in formalin were used to measure the lateral sulcus depth at the level of the temporal operculum, the length of the temporal operculum along its outer edge. The temporal operculum outlines were marked to further calculate its surface area [2].

Subject to the age periodization (1965), the material was divided into groups: early childhood (age 1-2; 8 preparations); the first period of childhood (age 3-7; $\mathrm{n}=18$ preparations); the second period of childhood (boys, age 8-12; girls, age 8-11; $\mathrm{n}=7$ preparations); adolescence (boys, age 13-16; girls, age 12-15; $\mathrm{n}=5$ preparations), youthhood (boys, age 17-21; girls, age $16-20 ; \mathrm{n}=9$ preparations).

The obtained data were processed by the variation statistical method using the Statistica 10.0 software. Due to the small number of samples, the median (Me) and the quartile range (Q25; Q75) were calculated to describe the average data, and non-parametric statistical methods were used to estimate the difference significance and the interrelational effect (U-MannWhitney test and Spearman's correlation coefficient).

\section{RESULTS AND DISCUSSION}

Based on the material of our study, we observed the following shapes of the temporal operculum - triangu$\operatorname{lar}(45 \%)$, scoop-net shaped (30\%), quadrangular (15\%), sickle-shaped (6\%) and unidentified (4\%) (Fig. 2).

The surface of the temporal operculum usually has tertiary fissures, the number of which varies from 1 to 6 . The number of tertiary fissures has been noted to be prevailing in the left hemisphere.

In early childhood, the average depth of the lateral sulcus at the temporal operculum level has no significant bilateral differences $(p=0.78)$. The average length of the temporal operculum in the left hemisphere is $77.3 \%$ above that on the right -28.9 [19.6; 31.4] $\mathrm{mm}$ and $16.3[14.6 ; 21.2] \mathrm{mm}(\mathrm{p}=0.02)$. The area of

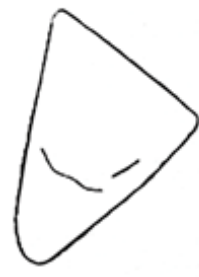

$\boldsymbol{a}$

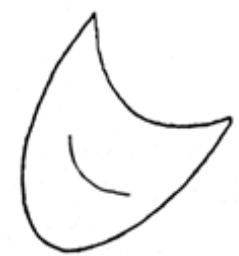

b

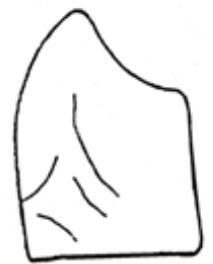

C

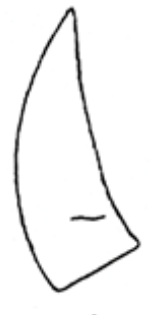

d
Fig. 2. Temporal operculum shapes: $a$ - triangular, $b$ - scoop-net shaped, $c$ - quadrangular, $d$ - sickle-shaped

the left temporal operculum statistically significantly exceeds that of the right (by 61.5\%) - 443.9 [301.5; $492.6] \mathrm{mm} 2$ and $274.3[206.1 ; 338.6] \mathrm{mm} 2(\mathrm{p}=0.03)$ (see Table 1).

In the first childhood period, the average depth of the lateral sulcus also reveals no significant bilateral difference $(p=0.72)$. The average length of the temporal operculum in the left hemisphere is $21.4 \%$ above that in the right one -27.8 [25.4; 31.1] $\mathrm{mm}$ and 22.9 [17.6; $26.8 \mathrm{~mm}$., however, the difference does not reach the level of statistical significance $(p=0.08)$. And only the area of the left temporal operculum reveals statistical significance exceeding the area of the right operculum by $26.9 \%-465.9[396.8 ; 503.0] \mathrm{mm} 2$ and 367.2 [290.1; 453.5] mm2 ( $\mathrm{p}=0.04)$.

In the second childhood period, adolescence and youth, the studied parameters have similar values in the right and left brain hemispheres ( $\mathrm{p}=0.10-0.94)$.

No statistically significant differences have been identified in the values in the adjacent age groups. This suggests that the temporal operculum reaches its final size in the early postembryonic development stages in the first year of life, when the most intensive growth of the brain is underway.

The correlation analysis showed a strong positive relationship between the temporal operculum length and its area $(\mathrm{r}=0.9 ; \mathrm{p}<0.001)$, as well as a moderately strong positive relationship between the lateral sulcus depth and the temporal operculum area $(\mathrm{r}=0.4 ; \mathrm{p}<0.001)$.

\section{CONCLUSIONS}

1. The most common shape of the temporal operculum is triangle.

2. The temporal operculum area in early childhood and the in first childhood period, as well as the length of the temporal operculum in early childhood, reveal statistically significant predominance in the brain left hemisphere.

3. From the age aspect, the depth of the lateral sulcus changes less significantly than the length and area of the temporal operculum. 
Table 1. Morphometric parameters of the temporal lobe in people in the age range of 1-21 yearsa

\begin{tabular}{|c|c|c|c|c|c|c|}
\hline Age group & Parameter & & $n$ & Min-Max & Me [Q25; Q75] & $p$ \\
\hline \multirow{6}{*}{$\begin{array}{l}\text { Early } \\
\text { childhood }\end{array}$} & \multirow{2}{*}{ Depth of the lateral groove, $\mathrm{mm}$} & Right & 8 & $29,4-38,6$ & $32,2[30,8 ; 36,6]$ & \\
\hline & & Left & 8 & $30,0-36,9$ & $32,4[30,75 ; 35,0]$ & 0,78 \\
\hline & \multirow{2}{*}{ The length of the temporal tire, $\mathrm{mm}$} & Right & 8 & $10,7-27,0$ & $16,3[14,6 ; 21,2]$ & \\
\hline & & Left & 8 & $16,0-35,6$ & $28,9[19,6 ; 31,4]$ & 0,02 \\
\hline & \multirow{2}{*}{ The area of the temporal tire, $\mathrm{mm}^{2}$} & Right & 8 & $171,2-436,4$ & $274,3[206,1 ; 338,6]$ & \\
\hline & & Left & 8 & $255,0-617,7$ & $443,9[301,5 ; 492,6]$ & 0,03 \\
\hline \multirow{6}{*}{$\begin{array}{l}\text { The first period } \\
\text { of childhood }\end{array}$} & \multirow{2}{*}{ Depth of the lateral groove, $\mathrm{mm}$} & Right & 18 & $28,0-37,4$ & $33,0[29,8 ; 33,9]$ & \\
\hline & & Left & 18 & $25,6-40,4$ & $33,2[29,8 ; 35,2]$ & 0,72 \\
\hline & \multirow{2}{*}{ The length of the temporal tire, $\mathrm{mm}$} & Right & 18 & $10,4-42,0$ & $22,9[17,6 ; 26,8]$ & \\
\hline & & Left & 18 & $9,6-40,3$ & $27,8[25,4 ; 31,1]$ & 0,08 \\
\hline & \multirow{2}{*}{ The area of the temporal tire, $\mathrm{mm}^{2}$} & Right & 18 & $157,0-693,0$ & $367,2[290,1 ; 453,5]$ & \\
\hline & & Left & 18 & $170,4-830,2$ & $465,9[396,8 ; 503,0]$ & 0,05 \\
\hline \multirow{6}{*}{$\begin{array}{l}\text { The second period of } \\
\text { childhood }\end{array}$} & \multirow{2}{*}{ Depth of the lateral groove, $\mathrm{mm}$} & Right & 7 & $28,5-39,3$ & $33,0[29,9 ; 34,7]$ & \\
\hline & & Left & 7 & $23,8-40,4$ & $32,5[27,7 ; 35,9]$ & 0,74 \\
\hline & \multirow{2}{*}{ The length of the temporal tire, $\mathrm{mm}$} & Right & 7 & $9,2-49,2$ & $28,5[15,5 ; 38,0]$ & \\
\hline & & Left & 7 & $10,6-51,6$ & $31,7[15,9 ; 37,1]$ & 0,94 \\
\hline & \multirow{2}{*}{ The area of the temporal tire, $\mathrm{mm}^{2}$} & Right & 7 & $156,8-730,7$ & $446,0[220,9 ; 518,9]$ & \\
\hline & & Left & 7 & $236,3-754,4$ & $434,1[325,1 ; 501,5]$ & 0,84 \\
\hline \multirow{6}{*}{ Adolescence } & \multirow{2}{*}{ Depth of the lateral groove, $\mathrm{mm}$} & Right & 5 & $21,2-41,6$ & $32,0[28,5 ; 33,1]$ & \\
\hline & & Left & 5 & $25,4-35,5$ & $32,0[28,5 ; 33,1]$ & 0,75 \\
\hline & \multirow{2}{*}{ The length of the temporal tire, $\mathrm{mm}$} & Right & 5 & $11,0-35,5$ & $15,1[12,5 ; 15,8]$ & \\
\hline & & Left & 5 & $12,0-43,2$ & $25,0[16,3 ; 38,7]$ & 0,17 \\
\hline & \multirow{2}{*}{ The area of the temporal tire, $\mathrm{mm}^{2}$} & Right & 5 & $132,5-568,0$ & $241,6[155,6 ; 328,6]$ & \\
\hline & & Left & 5 & $171,0-714,9$ & $443,7[207,0 ; 619,2]$ & 0,25 \\
\hline \multirow{6}{*}{ Youthhood } & \multirow{2}{*}{ Depth of the lateral groove, $\mathrm{mm}$} & Right & 9 & $11,8-42,1$ & $36,2[27,3 ; 37,3]$ & \\
\hline & & Left & 9 & $29,8-45,4$ & $35,6[31,8 ; 36,8]$ & 0,75 \\
\hline & \multirow{2}{*}{ The length of the temporal tire, $\mathrm{mm}$} & Right & 9 & $9,0-45,5$ & $19,4[10,0 ; 34,5]$ & \\
\hline & & Left & 9 & $15,2-40,6$ & $31,7[23,1 ; 36,7]$ & 0,17 \\
\hline & \multirow{2}{*}{ The area of the temporal tire, $\mathrm{mm}^{2}$} & Right & 9 & $159,0-957,8$ & $310,4[181,0 ; 470,9]$ & \\
\hline & & Left & 9 & $226,5-736,6$ & $555,7[415,8 ; 669,9]$ & 0,10 \\
\hline
\end{tabular}

4. The temporal operculum area correlates with the length of the temporal operculum to a greater degree than with the lateral sulcus depth.

The obtained data expands and complements the information available in the literature concerning human brain temporal operculum and shall be of interest to morphologists who deal with human brain structural issues. Detailed understanding of the temporal operculum surgical anatomy offers correct intraoperative orientation and helps choose the right option ensuring surgical access.

\section{REFERENCES}

1. Jeenbaev J. Age-related changes in the width of the cortex layers of fields 22,41 , and 42 of the human brain in postnatal ontogenesis / Science. Education. Equipment. - 2017. - Volume 58, No. 1. - P. 97-99.
2. Namkung H., Kim S.H., Sawa A. The Insula: An Underestimated Brain Area in Clinical Neuroscience, Psychiatry, and Neurology // Opinion. - 2017. Vol. 40. № 4. - P. 200-207 DOI: https://doi.org/10.1016/j. tins.2017.02.002.

3. Bykanov AE, Pitskhelauri D.I., Dobrovolsky G.F., ShKarubo M.A. Surgical anatomy of the insular area // Questions of neurosurgery. - 2015. - №4. - p. 48-60.

4. Speransky V.S., GLadilin YU.A. Dissymmetry in the structure and size of the temporal cap of the hemispheres of the human brain // Archive of Anatomy, Histology and Embryology. - 1986. - № 9. - p. 9-13.

5. GesCHWIND N. Cerebral dominance and anatomic asymmetry // New Engl. J. Med. -1972. - Vol. 287. P. 194-195. 